\title{
Study of total column atmospheric aerosol optical depth, ozone and precipitable water content over Bay of Bengal during BOBMEX-99
}

\author{
K K Dani, R S Maheskumar and P C S Devara* \\ Physical Meteorology and Aerology Division, Indian Institute of Tropical Meteorology, Dr. Homi Bhabha Marg, \\ Pune 411 008, India. \\ *e-mail: devara@tropmet.res.in
}

The spatial and temporal variations in aerosols and precursor gases over oceanic regions have special importance in the estimation of radiative forcing parameters and thereby in the refinement of general circulation models. Extensive observations of the columnar aerosol optical depth (AOD), total column ozone (TCO) and precipitable water content (PWC) have been carried out using the on-line, multi-band solar radiometers onboard ORV Sagar Kanya (Cruise \# SK 147B) over Bay of Bengal during 11th-28th August 1999. Aerosol optical and physical properties (optical depth and angstrom parameter) have been estimated at six wavelengths covering from UV to NIR (380$1020 \mathrm{~nm}$ ) while TCO and PWC have been determined using the UV band around $300 \mathrm{~nm}$ and NIR band around $940 \mathrm{~nm}$, respectively. Added, concurrent meteorological and satellite observations during this field phase of BOBMEX-99 have been utilized to investigate spectral-temporal variations of AOD, TCO and PWC in marine environment.

The results indicate lower AODs (around 0.4 at characteristic wavelength of $500 \mathrm{~nm}$ ) and size distributions with abundance of coarse-mode particles as compared to those aerosols of typical land origin. An interesting result that is found in the present study is the significant reduction in AOD at all wavelengths from initial to later part of observation period due to cloud-scavenging and rain-washout effects as well as signature of coastal aerosol loading. The clear-sky daytime diurnal variation of TCO shows gradual increase during post-sunrise hours, broad maximum during afternoon hours and gradual decrease during pre-sunset hours, which is considered to be due to photochemical reactions. The diurnal variation curve of PWC showed maximum $(\sim 4 \mathrm{~cm})$ during morning hours and gradual decrease $(\sim 3.5 \mathrm{~cm})$ towards evening hours, which are found to be greater as compared to typical values over land. Another interesting feature observed is that although the PWC values are very high, there was no proportionate or appreciable enhancement in $\mathrm{AOD}$ - a feature that can be utilized to infer composition of aerosols over the study region.

\section{Introduction}

Atmospheric aerosols, water vapour and ozone play important roles in the study of the Earth's climate system, because they interact with solar radiation and modify the climate. Aerosols interact with both incoming solar shortwave (SW) and the outgoing terrestrial longwave (LW) radiation as they either scatter or absorb or both scatter and absorb short and longwave radiation, and exert a more complex effect on climate (Charlson et al 1999 and references therein). They are generated from different sources and are distributed in the atmosphere through transport of air-masses over larger spatial scale. Maritime aerosols are mainly composed of three components. They are

- sea-salt particles produced over the sea surface by winds,

Keywords. Bay of Bengal; total column aerosol optical depth; size distribution; ozone; precipitable water content; ship; TOMS; satellite. 
- non-sea salt particles produced by photolytic decomposition of dimethyl sulphide and

- continental aerosols advected by offshore winds. Moreover, advection of continental aerosols over oceanic environment in the tropical region can cause large-scale climate perturbations particularly due to the presence of Inter Tropical Convergence Zone (ITCZ) which mixes the polluted northern hemispheric air mass with pristine southern hemispheric air mass vigorously.

In the past, aerosol measurements were made aboard the NASA research aircraft over Saudi Arabia, Arabian Sea and India as a part of summer monsoon experiment (MONEX-79). The important finding was the persistent haze layers that extend from the surface to approximately $6 \mathrm{~km}$ altitude over the entire region of southwest and southcentral Asia (Patterson and Grams 1981). These haze layers affect the radiative transfer in the atmosphere at both visible and infrared wavelengths, and also will have significant effects on regional climate and dynamics. These experiments also provided direct evidence of transport of dust from the Arabian peninsula to the Indian region across the Arabian Sea supplying large amounts of basic earth minerals which are potential neutralizers of acidic precipitation.

In order to understand the interactions between radiation and aerosols (of both natural and anthropogenic), transport and dispersion of trace species and pollutants in the atmosphere, oceanic heat budget etc., particularly over the tropical Indian Ocean, an international field experiment, namely, Indian Ocean Experiment (INDOEX) was conducted during the first field phase (FFP) in 1988 and the intensive field phase (IFP) in 1999 with participation of atmospheric chemists, aerosol experts, meteorologists and climate modelers from India, USA and Europe (Mitra 1999). PreINDOEX experiments also have been conducted during 1995 and 1999. These experiments integrate the multi-platform observations (satellites, aircraft, ships, surface stations and balloons) with one- and four-dimensional models to derive the regional aerosol forcing resulting from the direct, semi-direct and indirect effects. The major results obtained from the Indian experiments have been published in two special issues of the journal Current Science in 1999 and 2001. Some of the core findings from the IFP have appeared in one of the planned two special issues of the Journal of Geophysical Research in 2001. The major findings of these experiments is the Indo-Asian haze extending up to $3 \mathrm{~km}$ high with single scattering albedo around 0.9 both inland and over open ocean and its impact on tropical rainfall patterns and hydrological cycle with implications to global climate (Ramanathan et al 2001).
As discussed above, the spatial and temporal variations in aerosols and precursor gases over oceanic regions have special importance during the monsoon period in the estimation of radiative forcing parameters and thereby in the refinement of general circulation models (Lohmann et al 1999). In order to understand some of the above aspects particularly during the southwest (SW) monsoon season, a multi-institutional national experiment, namely, Bay Of Bengal Monsoon EXperiment (BOBMEX) was planned by the Department of Science and Technology (DST) in collaboration with other government agencies and universities (DST 1996; 1998). This experiment (BOBMEX99) was conducted in the central and north Bay of Bengal during July - August 1999. The fundamental objectives of the BOBMEX are two fold:

- to study the nature of variation of the atmosphere, ocean and their coupling during intensification and propagation of monsoon; and - to examine the above parameters during different phases of convective activity.

Several atmospheric and oceanic observations were carried out onboard research vessels along with enhanced observations at nearby coastal and island stations. In the present contribution, the multi-band solar radiometric observations of columnar aerosol optical depth (AOD), ozone (TCO) and precipitable water content (PWC) that have been carried out onboard ORV Sagar Kanya (Cruise SK \# 147B) over Bay of Bengal during 11th-28th August 1999 are presented. The details of the experiments and results obtained are discussed in conjunction with the satellite products and ship deck-level meteorological parameters during the period of observations.

\section{Cruise track and instrumentation}

Two scientific cruises, viz., Cruise\#147A (I phase) and \# 147B (II phase) were organized onboard Ocean Research Vessel Sagar Kanya along with the naval vessel Sagardhwani during the active phase of the southwest (SW) monsoon during July - August 1999. The present paper deals with the measurements made with collocated on-line; multi-band solar radiometers and automatic weather monitor during phase II of the cruise. Figure 1 shows the cruise track followed in the experiments. DS3, DS4 and TS2 depicted in the figure are the positions of the data buoys in the central Bay. During phase II, the ship commenced her journey from Paradeep on August 11th, 1999 and terminated on August 31st, 1999 at Chennai. During this journey along the cruise path, the ship was made stationary for ten days at DS4 and for one day each at DS3 and TS2 to make synchronous observations with the buoys. 


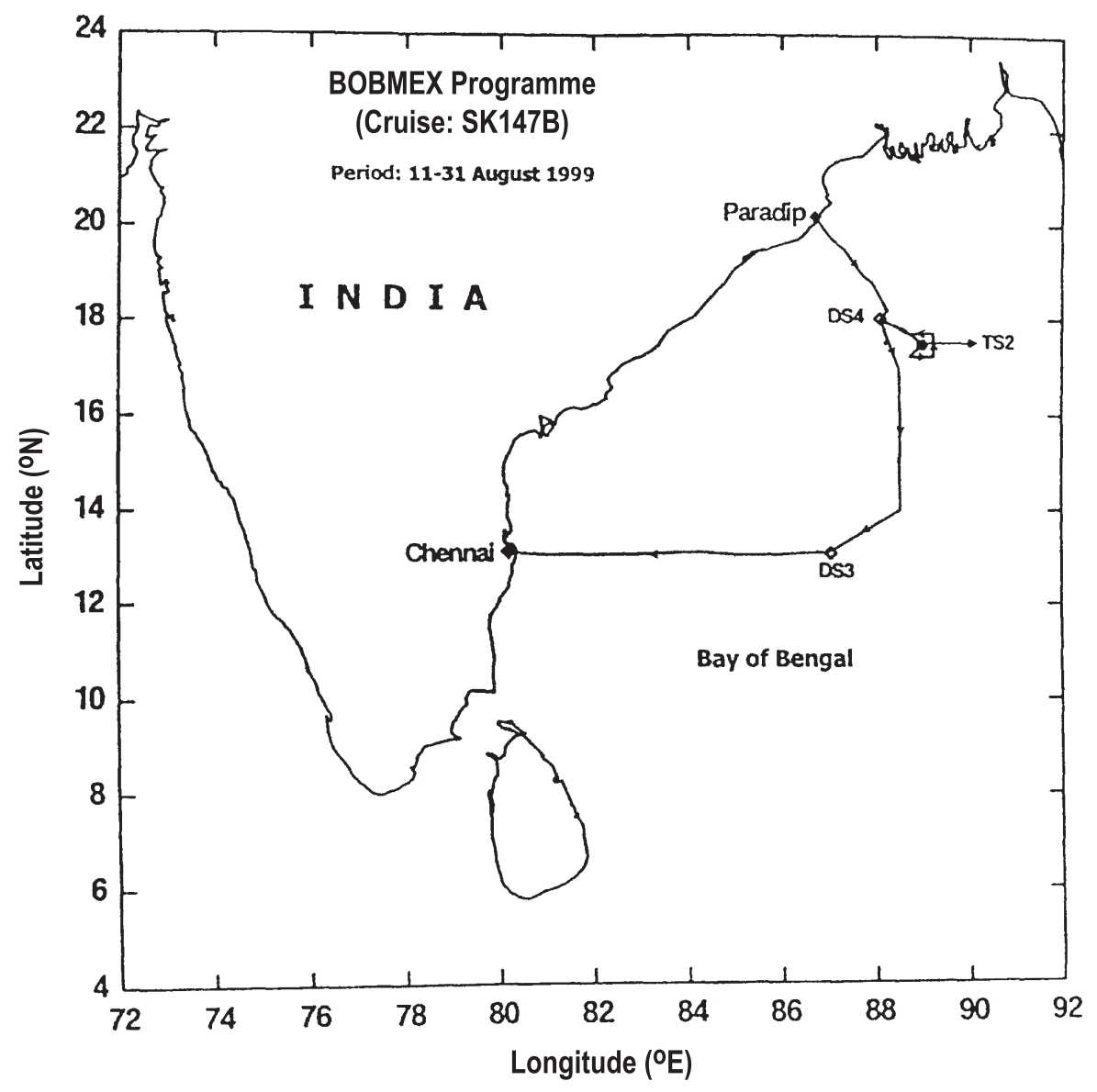

Figure 1. Map showing the cruise path followed in the experiment.

Measurements were made using the compact, on-line, multi-band solar radiometers namely, sunphotometer and ozone monitor (Microtops II, $\mathrm{m} / \mathrm{s}$. Solar Light Control Inc. USA). The instruments were thoroughly checked for calibration. Inter-comparison experiments were also performed before their deployment for the measurements. These instruments were operated at the front end of the ship at about 10 meters above the sea surface in order to minimize the effects due to pitch and rolling of the ship and also to avoid the contamination due to smoke emanating from the chimney of the ship. This arrangement also facilitated making the observations free from contamination due to sea spray particularly during the rough sea conditions.

The radiometers used in the present experiment yield instantaneous estimates of aerosol and gaseous optical depths as opposed to conventional solar radiometers. The sunphotometer provides height-integrated AOD (or extinction) at six wavelengths covering from UV to NIR and hence the size distribution of aerosols, and the other radiometer (ozonometer) determines total column ozone (using the UV band) and also precipitable water content (using the NIR band) simultaneously. Both the radiometers were mounted on a single wooden platform which is in turn fixed to a tripod for achieving high stability, time synchronization between observations and easy focusing of radiometers to the sun's disc. Sufficient care was taken while focusing the radiometers to the solar disc, particularly when the ship is in motion. Each radiometer is equipped with internal barometer/altimeter for monitoring of atmospheric pressure and altitude of the experimental location. The global positioning system (GPS) receiver provides the geographical coordinates of the site, which are used for estimating the local air mass. The main operating parameters of these portable radiometers are presented in table 1 . More details about these radiometers have been published elsewhere (Devara et al 2001). The ship deck-level meteorological observations (temperature, wind and relative humidity) were collected simultaneous to the radiometric measurements of atmospheric aerosols, ozone and water vapour over the sea region.

The radiometers were operated initially by keeping the cover closed for the optical blocks (consist- 
Table 1. Main specifications of the portable, on-line, aerosol, ozone and water content monitor deployed in the experiment.

\begin{tabular}{lll}
\hline Radiometer & \multicolumn{1}{c}{ Parameter } & \multicolumn{1}{c}{ Description } \\
\hline Sunphotometer & Aerosol optical depth & \\
& Filter wavelengths & $0.38,0.44,0.5,0.675,0.87$ and $1.02 \mu \mathrm{m}$ \\
& & $(0.005-0.01 \mu \mathrm{m}$ FWHM $)$ \\
\hline Ozonometer & Ozone & \\
& Filter wavelengths & $0.3055,0.3125$ and $0.32 \mu \mathrm{m}$ \\
& & $(0.005 \mu \mathrm{m}$ FWHM $)$ \\
\hline & Precipitable & \\
water content & \\
& Filter wavelengths & 0.94 and $1.02 \mu \mathrm{m}$ \\
& $(0.01 \mu \mathrm{m}$ FWHM $)$ \\
& Field of view & $<2.5^{\circ}$ \\
Detector & GaP Photodiode \\
Amplifier & FET-input operational amplifier \\
Data acquisition & 20 -bit resolution A/D converter \\
Scan speed & All filter scan within 10 seconds \\
Scanning method & Parallel \\
Data analysis & On-line \\
Recording format & Optical depth versus solar zenith angle \\
Display & LCD (3.5 digits) \\
Power source & Alkaline batteries (12V DC) \\
Portability & Compact \\
Dynamic range & $3 \times 10^{4}$ \\
Data storage & 800 records \\
&
\end{tabular}

ing of windows, filters etc.). During this period, the instrument stores the background values for all the filters. In the next few seconds, on removing the cover, it collects a set of over 25 observations for each filter. The average value, thus obtained for each filter, was used to compute the spectral variation of columnar AOD, ozone and water content instantaneously, and are depicted on the display for a quick look, and stored in the memory.

\section{Calibration and inter-comparison experiments}

The quality of calibration depends strongly on the clarity of the atmosphere when the Langley method is used. The radiometer used in the present study does not require a priori knowledge of the absolute calibration constants because the linear regression fitted line passing through the data points is used to calculate the optical depth. However, as explained by Stair and Ellis (1968), absolute calibration of the instrument can be obtained by referencing the extrapolated zero air mass signal $\left(F_{0}\right)$ to the known values of incident solar radiation. $F_{0}$ values obtained at different wavelengths from day to day should remain constant for clear stable days and any variations in it over a period of time reveal changes (drift) in the system characteristics. Determination of total optical depth is sen- sitive to small errors in the measurement of $F_{0}(\lambda)$. It is difficult to determine $F_{0}(\lambda)$ from observations on a single day because of the stringent requirements on the optical stability of the atmosphere (Reagan et al 1986). Therefore, it is essential to calibrate the radiometer based on the average $F_{0}(\lambda)$ value determined from all the stable day Langley plots over a period of time. Such calibration procedures using weighted average intercepts, suggested by Young (1980) have been adopted in the present study. The initial calibration of the sunphotometer version of the MICROTOPS II was performed by a transfer of calibration constants from reference instruments which were calibrated by the Langley plot technique at a noise-free high altitude site.

Apart from constant monitoring of $F_{0}(\lambda)$ which serves as calibration constant for each channel, inter-instrumental comparison of AOD at either exact or near-synchronous wavelengths of all-thetime near-simultaneously operated multi-channel solar radiometer and spectroradiometer has been carried out periodically to ensure the stability and reliability of AODs, ozone and water content measured using the MICROTOPS radiometers. Inter-comparison experiments have also been performed during the recently conducted INDian Ocean EXperiment (INDOEX). In all, the agreement is found to be fairly good.

The differential optical absorption and scattering (DOAS) method has been followed in the ozone 


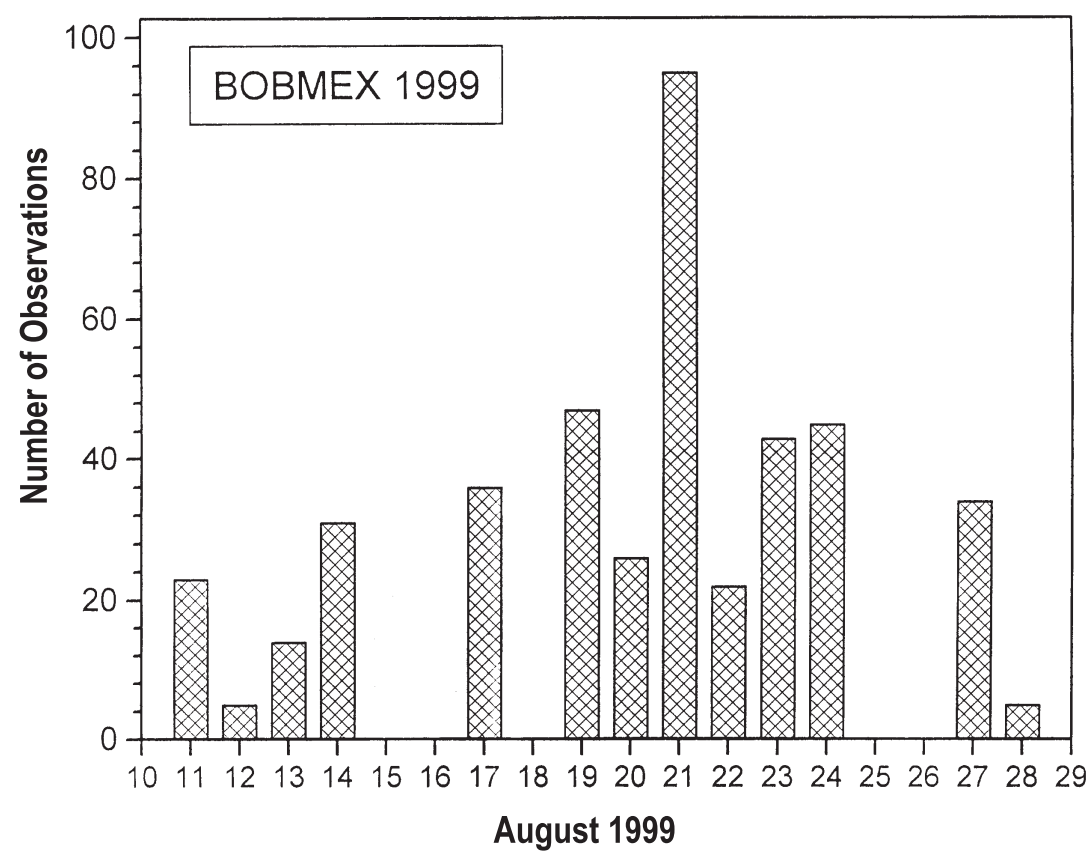

Figure 2. Details of observations carried out during the cruise period.

monitor which measures both total column ozone and precipitable water content. The total column ozone was measured by using three wavelengths, namely, 300, 305 and $312 \mathrm{~nm}$. Since the calculations based on any single pair of these wavelengths show air mass dependence effect, the derived ozone values have been corrected using the values obtained from the wavelength pairs, 300-305 $\mathrm{nm}$ and 305$312 \mathrm{~nm}$. It is customary to ignore the aerosol scattering when ozone is computed from two pairs of wavelengths. Using very closed spaced wavelengths that minimize the difference in the absorption coefficients at the two wavelengths reduces the aerosol effect. An important advatage of the present instrument as compared to many in situ techniques is that an ozone measurement can be made during a few seconds when the sun is open. The ozonometer has been originally calibrated using the Langley method of Mauna Loa Observatory (MLO) and compared its performance with coincident Dobson and Brewer spectrometers. The column ozone measurements made in the present study have also been compared with ozone retrievals from the TOMS instrument aboard NASA satellite.

The column water vapour was measured based on a pair of radiometric measurements in the near-infrared wavelengths of 940 and $1020 \mathrm{~nm}$. The $940 \mathrm{~nm}$ filter is located in a strong water vapour absorption band, while the $1020 \mathrm{~nm}$ filter is affected only by aerosol scattering. Although the water vapour version of Microtops II has been originally calibrated at MLO and compared with LED sunphotometers at Geromimo Creek Observatory, periodic inter-comparison experiments have been conducted using local radiometersonde ascents. The calibration procedures involved in the ozone and water vapour versions of Microtops II have been detailed in Morys et al (2001).

\section{Observations and analysis}

The observations were made from morning till evening on the days when the sky was nearly free from visible clouds, and none were near the line-ofsight to the sun. The observations were repeated at an interval of about 10 minutes when the airmass changes rapidly during the post-sunrise and pre-sunset periods. Data obtained with each filter were corrected for background noise by off-setting the detector output to zero by completely covering the filter before it is exposed to the sun. The procedure is repeated for all the data sets recorded for different solar zenith angles. The experiment could be conducted on a total of 13 days under cloud-free conditions during the cruise period (figure 2). Of which, through-out-the-day observations were collected at 10-minute intervals, on two days (21st and 23rd August 1999) associated with clear-sky conditions. The columnar aerosol optical depth, size distribution, ozone and precipitable water content were estimated from each 
day's observations as described in the following sub-sections.

\subsection{Retrieval of AOD, size distribution, ozone and precipitable water content}

The optical depth of the atmosphere can be determined from the Beer-Bouger-Lambert law, expressing attenuation $(\alpha)$ of the direct solar beam in the atmosphere in the form:

$$
F(\lambda)=F_{0}(\lambda) e^{-\alpha(\lambda) m(\chi)},
$$

where $F(\lambda)$ is the monochromatic solar irradiance reaching the instrument detector at wavelength $\lambda ; F_{0}(\lambda)$ is the irradiance incident on the top of the atmosphere and it can be used to self calibrate the system; $m$ is optical air mass which is a function of solar zenith angle $\chi\left(m=\sec \chi\right.$, for $\left.\chi \leq 75^{\circ}\right)$. The slope of the straight line fitted to the data points of the plot of natural logarithm of radiometer output versus air mass, slope gives the atmospheric total optical depth $\left(\tau_{\text {total }}\right)$.

$$
\tau_{\text {total }}(\lambda)=\tau_{m}(\lambda)+\tau_{g}(\lambda)+\tau_{a}(\lambda)
$$

where $\tau_{m}(\lambda)$ is optical depth due to air molecules (Rayleigh scattering); $\tau_{g}(\lambda)$ is optical depth due to gas molecular absorption (i.e., due to gases that are expected to contaminate the measurements, which may be useful for determining the columnar content of atmospheric species or gases such as ozone, water content) and $\tau_{a}(\lambda)$ is optical depth due to aerosol particles.

$\tau_{m}(\lambda)$ can be evaluated by knowing the refractive index of air molecules and molecular number density of air at standard atmospheric temperature and pressure. Among many published values we have adopted the correction procedure suggested by Young (1981) and Teillet (1990) for the depolarization ratio (Devara et al 1996). $\tau_{g}(\lambda)$ can be computed from absorption cross-section of different gas molecules at any wavelength and from known number density of absorbing gas. This parameter, measured at two different wavelengths representative of absorption and transmission lines of any gas, can be used for determining column density of various trace gas species. $\tau_{a}(\lambda)$ can be computed by subtracting the combined contributions of $\tau_{m}(\lambda)$ and $\tau_{g}(\lambda)$ from $\tau_{\text {total }}(\lambda)$.

The AOD at $1.020 \mu \mathrm{m}$ is also calculated based on the extra-terrestrial radiation at that wavelength, corrected for sun-earth distance, and the groundlevel measurements of the radiation at $1.020 \mu \mathrm{m}$. This optical depth at the near-infrared (NIR) in conjunction with those from the sunphotometer at ultraviolet (UV) and visible (V) regions were utilized to retrieve columnar aerosol size distribution by applying the constrained linear inversion method as explained in King et al (1978) and as applied in our earlier publications (for example, Pandithurai et al 1997). A brief description of this retrieval procedure is given in the paragraphs to follow.

Having obtained AOD at different wavelengths, aerosol size distribution (ASD) can be determined by following the inversion scheme suggested by King et al (1978), and King (1982) which connects the AOD and ASD as

$$
\tau_{a}(\lambda)=\int_{0}^{\infty} \pi r^{2} Q_{\text {ext }}(x, m) n_{c}(r) \mathrm{d} r,
$$

where $r$ is the particle radius, $m$ is the complex refractive index of aerosol particles; $Q_{\text {ext }}(r, \lambda, m)$ is the Mie extinction efficiency parameter, $n_{c}(r)$ is the columnar aerosol size distribution (i.e., the number of particles per unit area per radius interval in a vertical column through the atmosphere). In the complex refractive index, the real quantity represents contribution due to particulate scattering while the imaginary quantity denotes the particles' absorption. In the present analysis, the imaginary component of $m$ is assumed to be negligible as this value, at present, is very small for the aerosol particles present over the experimental station.

Since $n(r)$ cannot be written analytically, a numerical approach is followed to separate $n_{c}(r)$ into two parts as $n_{c}(r)=h(r) . f(r)$, where $h(r)$ is rapidly varying function with $r$ and $f(r)$ is slowly varying. Hence the above equation changes to

$$
\tau_{a}(\lambda)=\sum_{j=1}^{q} \int_{r_{j}}^{r_{j+1}} \pi r^{2} Q_{\text {ext }}(r, \lambda, m) h(r) f(r) \mathrm{d} r .
$$

In the above equation, the quadrature error will be less if $f(r)$ is assumed to be constant. In that case, a system of linear equations results, which may be written as

$$
\begin{aligned}
\tau_{a}(\lambda) & =A f(r)+\varepsilon \\
\text { where } \quad A & =\int \pi r^{2} Q_{\text {ext }}(r, \lambda, m) h(r) \mathrm{d} r
\end{aligned}
$$

and $\varepsilon$ is an error which arises due to deviation between the measured $\tau_{a}$ and theoretical $\tau_{a}(=$ $\left.\sum A_{i j} f_{i}\right)$. Inititally, Junge exponent $(\nu)$ is computed from the wavelength dependence of aerosol optical depth and used as zero-order weighting function $h^{0}(r)$. By using $h^{0}(r)$ as an initial guess, first order $f^{(1)}$ values are evaluated using the equation

$$
f^{(1)}=\left(A^{T} S_{\varepsilon}^{-1} A+\gamma H\right)^{-1} A^{T} S_{\varepsilon}^{-1} \tau_{a},
$$



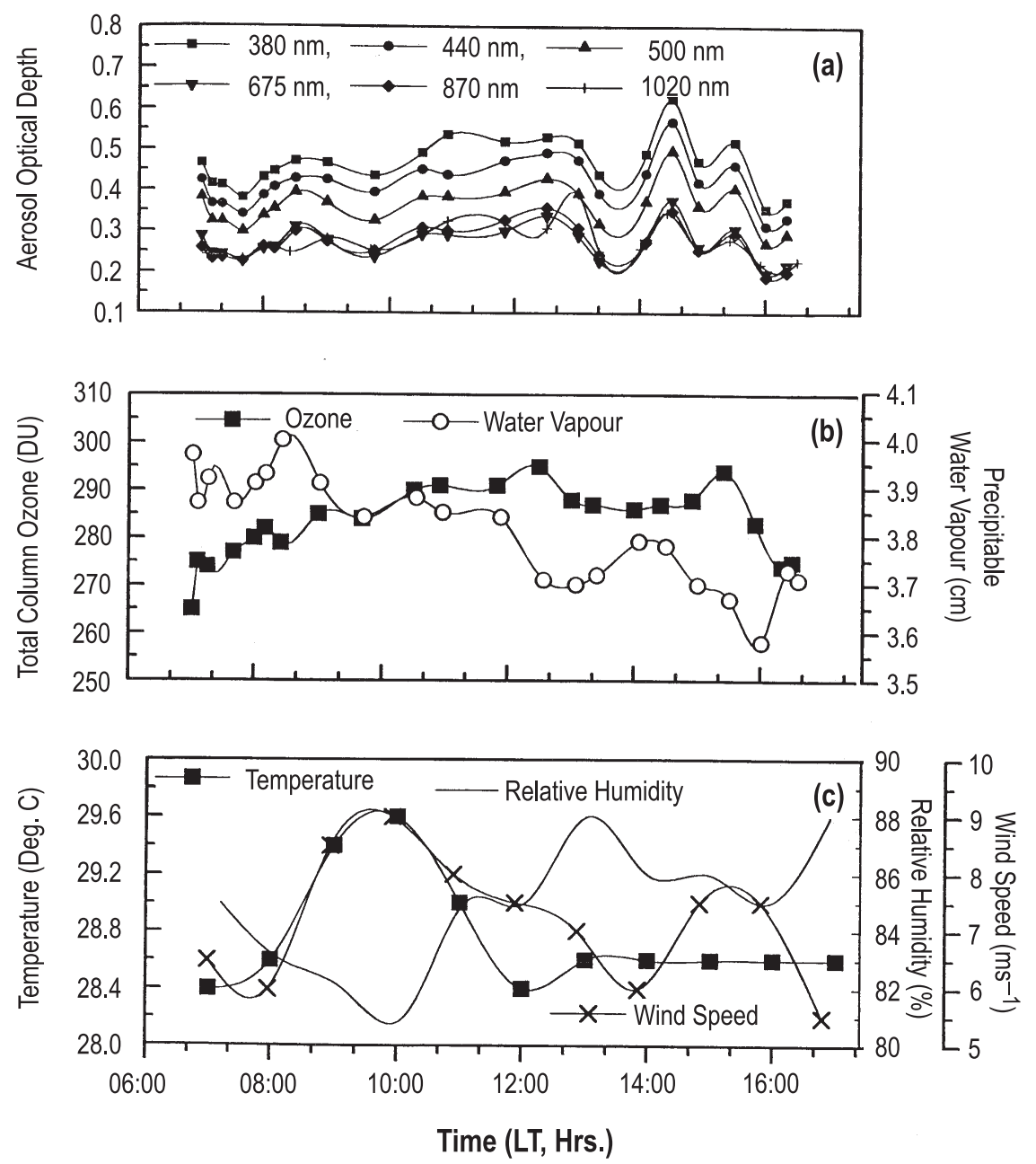

Figure 3. Spectral-temporal variations in (a) AOD, (b) TCO and PWC together with (c) deck-level meteorological parameters observed on August 21st, 1999.

where $\gamma$ is non-negative Lagrangian multiplier and $S_{\varepsilon}$ is the measured covariance matrix, $H$ is a mean diagonal matrix and superscript $T$ denotes matrix transposition. This iteration procedure is repeated till the observed $\tau_{a}$ comes closer to the re-computed $\tau_{a}$.

\section{Results and discussion}

The columnar AOD and size distribution, ozone and water content have been estimated, as explained above, from each day's observations, particularly when the ship was made stationary for making special measurements in synchronization with the buoys. The spectral and temporal variations of these parameters under different meteorological conditions revealed interesting results. They are presented and discussed in the sub-sections to follow.

\subsection{Spectral-temporal variations in $A O D$, TCO and $P W C$}

The temporal variations in total column AOD at different optical channels of the radiometer, ozone and precipitable water content together with concurrent deck-level selected meteorological parameters observed on a typical clear-sky day (August 21st, 1999) are shown plotted in figure 3 as separate frames (a), (b) and (c) respectively. The frame (a) depicts time variations of AOD at different wavelengths which clearly indicates more or less a systematic spectral dependence according to classical Mie scattering theory except at the NIR wavelengths. These features can be ascribed to the abundance of fine aerosol particles of continental origin that might have transported from land to oceanic region. The merging between the time variation of AOD at NIR wavelength could be due to interaction between aerosols of both land and 

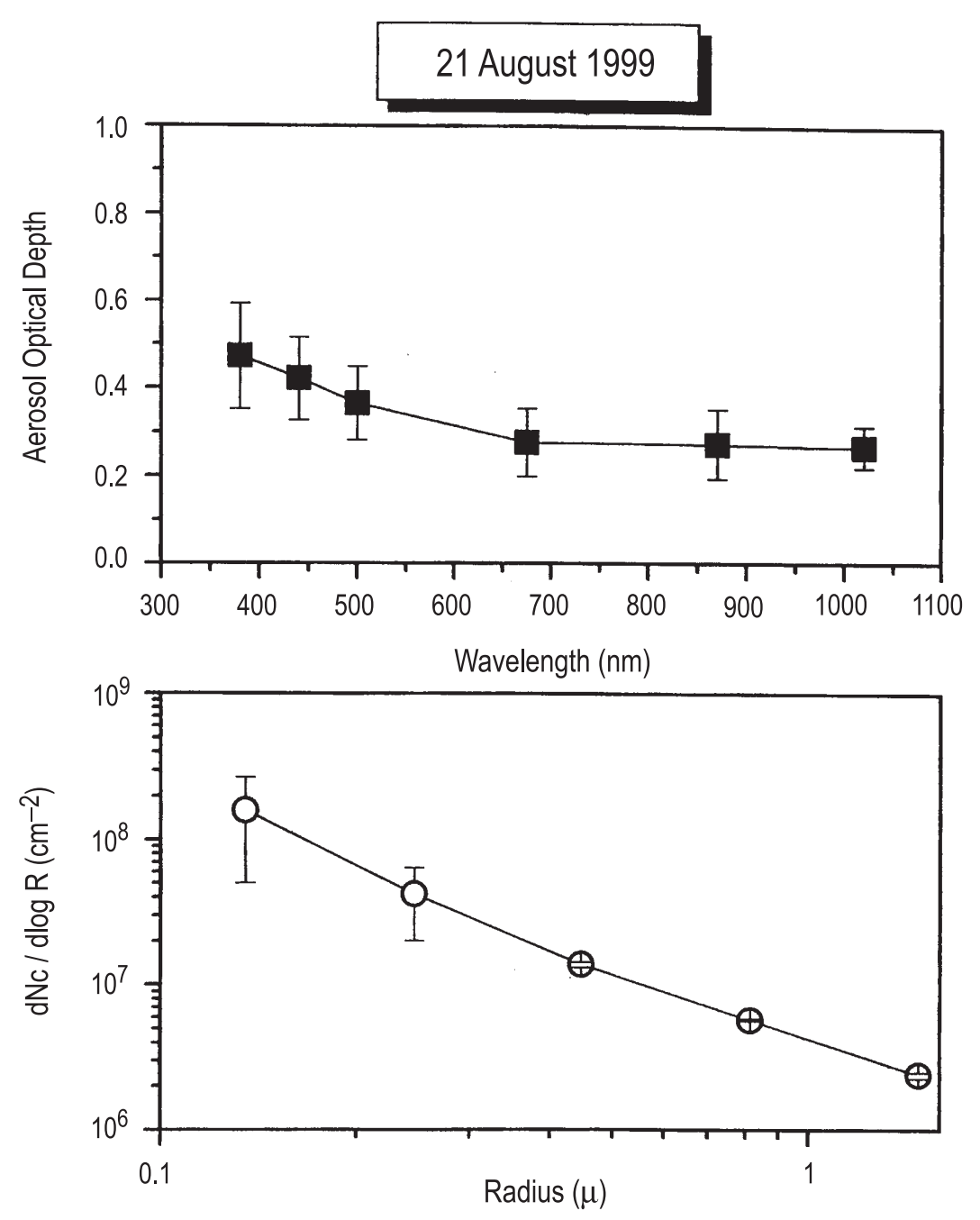

Figure 4. Spectral characteristics of AOD and corresponding size distribution observed on August 21st, 1999. Vertical bars indicate standard errors in the parameter.

oceanic origins. From frame (b) in which the time variations between TCO and PWC are compared, the striking feature that can be seen is the opposite behaviour between these two parameters. In contrast to temporal variation in PWC over land, it exhibited larger values (around $3.9 \mathrm{~cm}$ ) in the morning hours and gradual decrease (up to about $3.55 \mathrm{~cm}$ ) towards evening hours. The TCO also showed gradual increase in the morning hours and decrease towards evening hours with a broad maximum during the afternoon hours, which can be explained on the basis of photochemistry. Comparison between the frames (a) and (c) reveals the influence of wind on the enhancement in AOD during pre-noon and post-noon periods. It may be noted that although the wind speeds are high during the pre-noon period as compared to post-noon, enhancement in AOD is not observed. This may be due to increase in temperature during the period, which might have affected the surface area of some of the aerosols present in the sensing region. Nevertheless, the effect of wind is quite evident on AODs observed during the post-noon period. Comparison between the frames (a) and (b) also reveals a correspondence between AOD and PWC which suggests the growth of aerosol particles on the occasions associated with higher PWC values. The opposite relationship observed in the time variation in TCO with those in PWC or AOD may be attributed to the mixing of significant fraction of observed ozone of stratospheric origin with aerosol-rich air from below.

Figure 4 displays the mean spectral dependence of AOD and corresponding aerosol size distribution observed on August 21st, 1999. The spectral variation of $\mathrm{AOD}$ exhibits high $\mathrm{AOD}$ at smaller wavelengths and vice-versa as expected from the Mie theory except a slight enhancement in AOD at $870 \mathrm{~nm}$ which may be due to interference of weak water vapor absorption band. The size spec- 


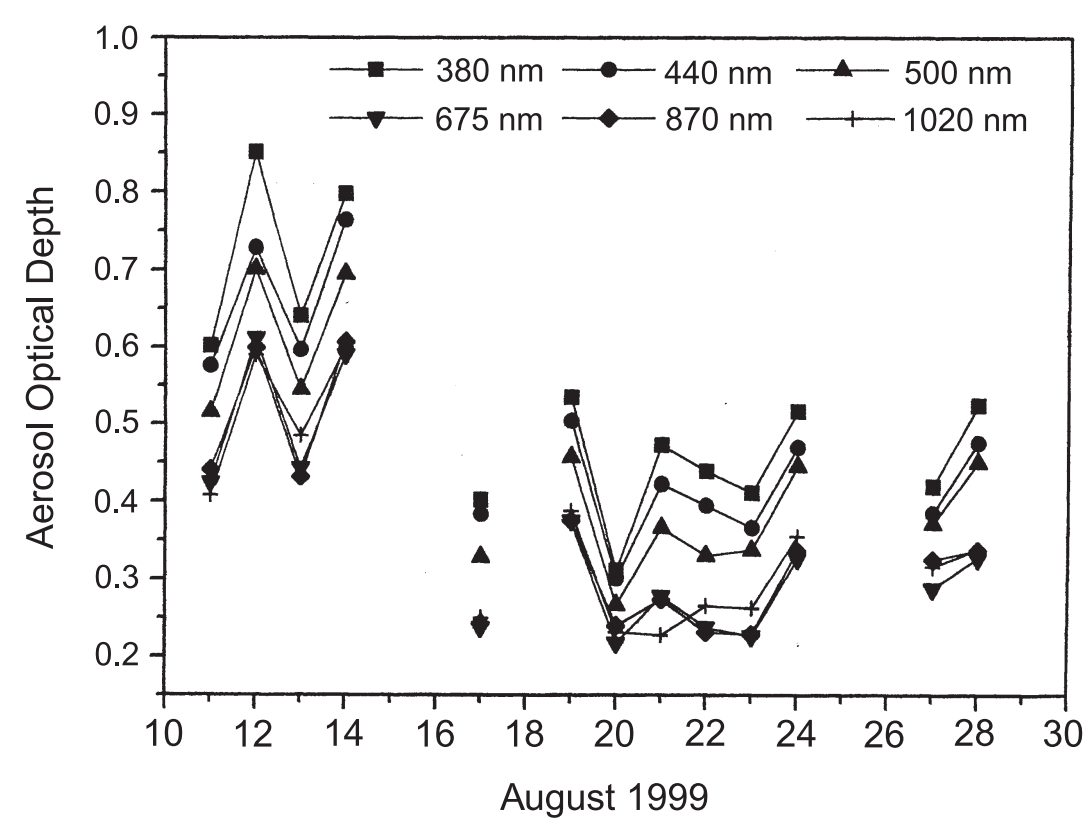

Figure 5. Day-to-day variations in spectral dependence of AOD during the cruise period.

tra exhibits power-law type distribution indicating greater concentrations of smaller aerosol particles of radius around $0.15 \mu \mathrm{m}$ and gradual decrease of concentration of larger particles of radius greater than $1.5 \mu \mathrm{m}$.

\subsection{Variations in aerosol and gaseous characteristics during the cruise period}

The day-to-day variations in spectral dependence of AOD during the entire period are shown in figure 5. The gaps in the plot between the period from 14th to 19th and again between 25th and 26th August 1999 are due to rain in the experimental area. It is interesting to note that the AOD variations during the period of cruise can be classified into three groups. Group 1 corresponding to 11th to 14th August indicating higher AODs due to transport of aerosols from land to ocean which otherwise implies advection of pollutants from the land to pristine air-mass, group 2 between 19th and 24th August indicating AOD values ranging from 0.2 to 0.5 exhibiting major part of marine air-mass with less portion of land aerosols (observational site is about $400 \mathrm{~km}$ away from the coast) and group 3 between 27th and 28th August indicating low to high AOD suggesting changeover from marine (pristine) to land (polluted) air-mass. The fall in AOD from group 1 to group 2 and also from group 2 to group 3 is considered to be due to cloud-scavenging and rain wash-out processes.

In order to explain these results in a more detailed way, a back trajectory analysis was per- formed using the NOAA hybrid single-particle Lagrangian integrated trajectory (HYSPLIT 4) model (Draxler and Hess 1998). This analysis provides lat-long distributions of kinematic wind field including horizontal and vertical wind velocities. The trajectories were computed at 500, 1000 and $1500 \mathrm{~m}$ AGL and for the ship track during the cruise period. Figure $6(\mathrm{a}$ and $\mathrm{b})$ shows trajectories (48 hours backward) on some selected days of observations. These trajectories basically reveal the transport of air mass and hence the sourcesink characteristics of aerosols in the experimental and adjoining regions. It is clear from the figure that the observations were influenced by the combined air mass of both ocean and land origin on 12th, 14th and 28th August 1999. Although, it is evident from the figure that air mass originated from land, its exchange with the ocean aerosols both horizontally as well as vertically might have significantly influenced the observed AODs on these days. In contrast, the observations were influenced mostly by pristine air mass between 19th and 24th August 1999. Thus the observed changes in AOD and wind field are consistent.

The day-to-day variations in selected mean meteorological parameters such as wind speed, temperature and relative humidity over the entire phase II of the BOBMEX are shown plotted in figure 7. On close examination of this figure in comparison with such variations observed in AOD in figure 5 reveals that the higher AODs observed during 11th-14th August and on 21st, 24th and 28th August 1999 may be due to strong wind speed 

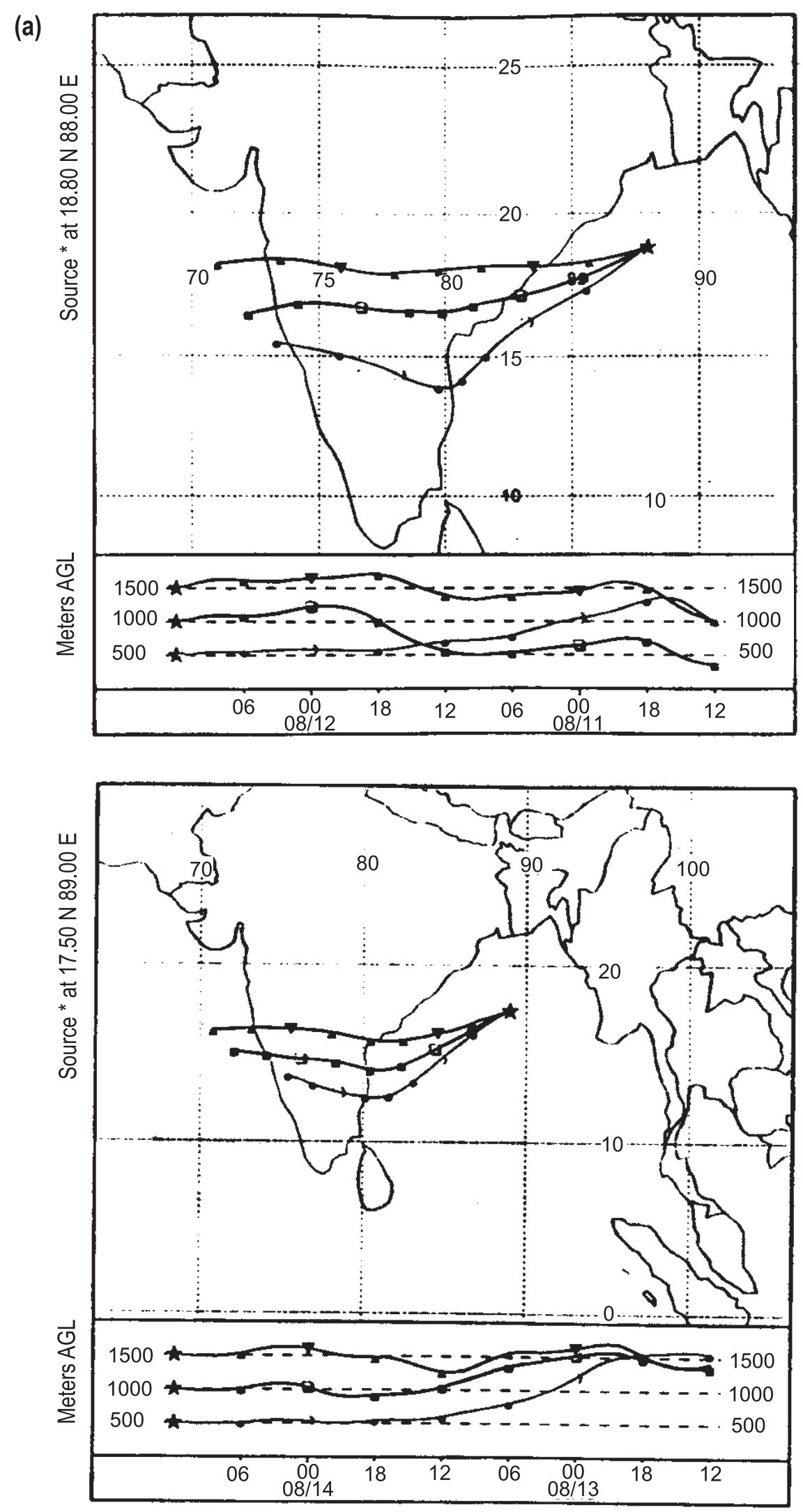

Figure 6. (Continued) 


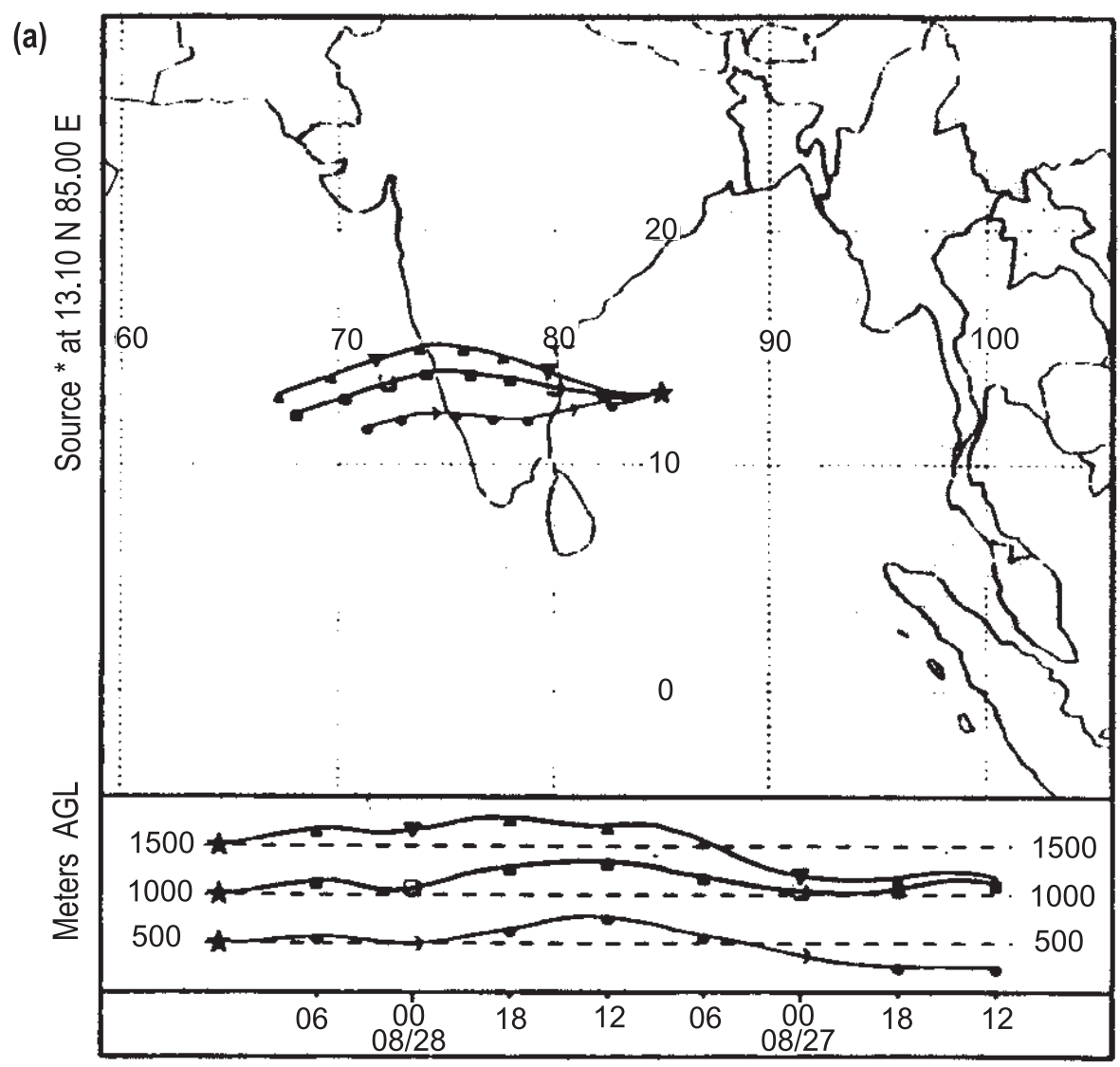

Figure 6. (Continued)

varying between 10.5 and $12.5 \mathrm{~ms}^{-1}$ and associated relative humidity of more than 80 per cent.

The advection of land aerosols into the sea in the beginning of the cruise and vice-versa at the end of the cruise can be seen clearly also from figure 8 which portrays the day-to-day variations in the size spectra of aerosols. The size spectra on 11th, 12th and 13th August show bimodal distribution with the dominance of accumulation-mode particles representing more aerosols of land origin. The spectrum on 19th August shows bimodal distribution which may be due to recovery of aerosol particles in the atmosphere overlying sea surface after precipitation. The spectra from 20 th to 24 th August show power-law type distribution representing pristine air-mass. In the return leg of the ship, the aerosol size spectra show bimodal distribution indicating the presence of both marine and land aerosols. These two spectra also reveal the intrusion of fresh aerosols after rain spells on 25th and 26th August 1999 in the experimental region.

From the log-log plot of AOD versus wavelength, the Angstrom or turbidity coefficient $(\beta)$ and wavelength exponent $(\alpha)$ have been derived as explained in our earlier publications (Maheskumar et al 2001). These aerosol optical and physical parameters computed for each observational day are plotted in figure 9. Both these parameters are found to be maximum on August 21st, 1999 indicating more attenuation of solar light due to aerosols and presence of abundance of sub-micron sized aerosol particles on that day. The influence of intermittent rainfall that had occurred during the observational period on both the parameters is also evident. Minimum extinction or maximum marinereaching solar flux, and minimum values of $\alpha$ indicating presence of coarse-mode aerosol particles are found on August 20th and 27th, 1999, respectively. Higher values of $\beta$ (more attenuation) and lower values of $\alpha$ (contribution from bigger aerosol particles) observed at the beginning and ending of the journey indicate the exchange of air-mass between land and sea regions which is consistent.

The spectral distribution of AOD and corresponding aerosol size distribution, averaged over the entire cruise period, are shown plotted in figure 10. The mean wavelength exponent $(\alpha)$ and Angstrom turbidity coefficient $(\beta)$ observed over the entire study period are also indicated in the figure. It is quite interesting to note that although the overall dependence of AOD follows the Mie theory, the range of AOD values is small i.e., from 0.35 to 0.45 which may be due to the influence of intermittent rain and associated cloud-scavenging 
(b)
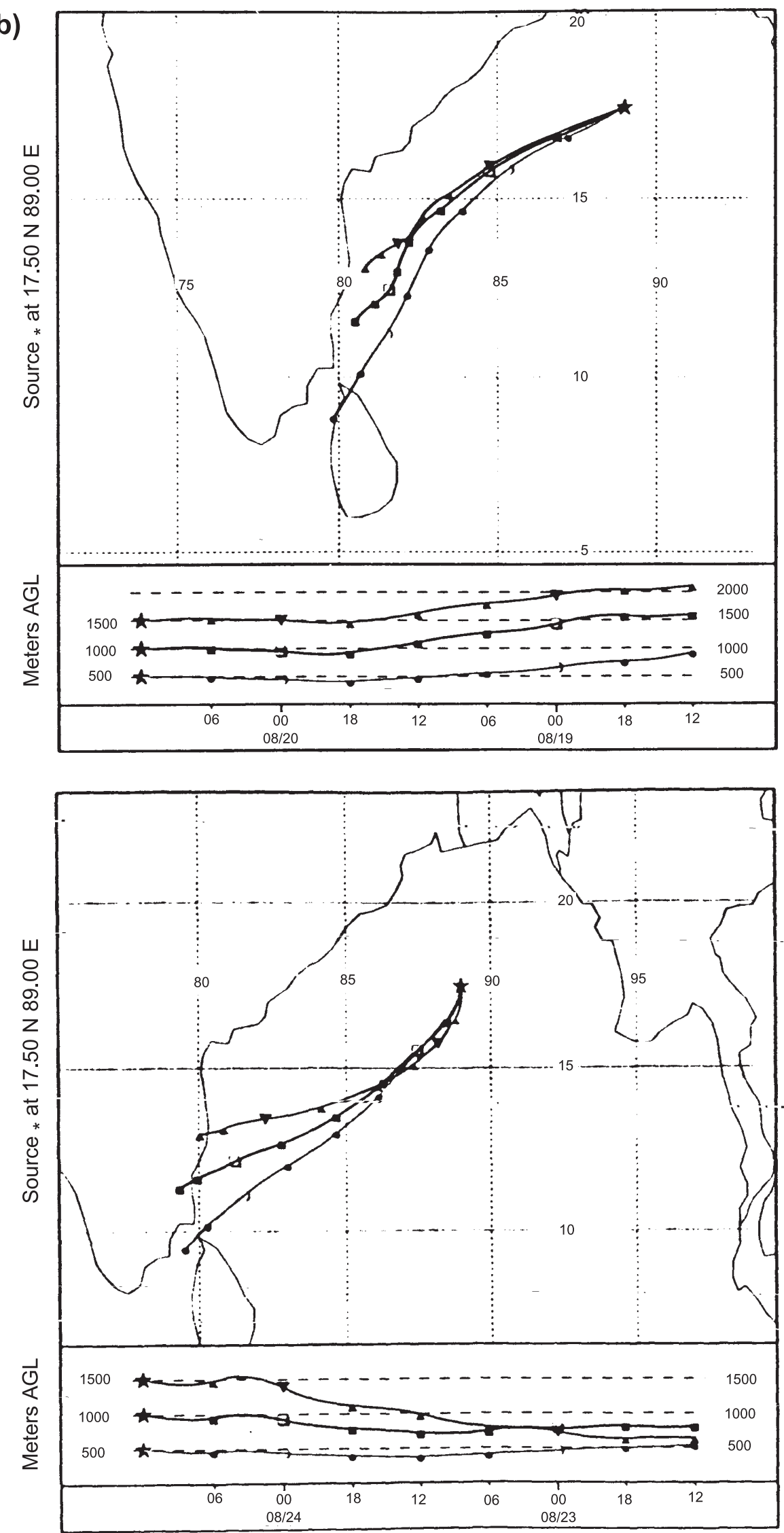

Figure 6(a) and (b). Back trajectory analysis of wind field and associated air mass characteristics on some selected segments of the cruise path. The trajectories are calculated up to 2 days backward using the HYSPLIT-4 program. 


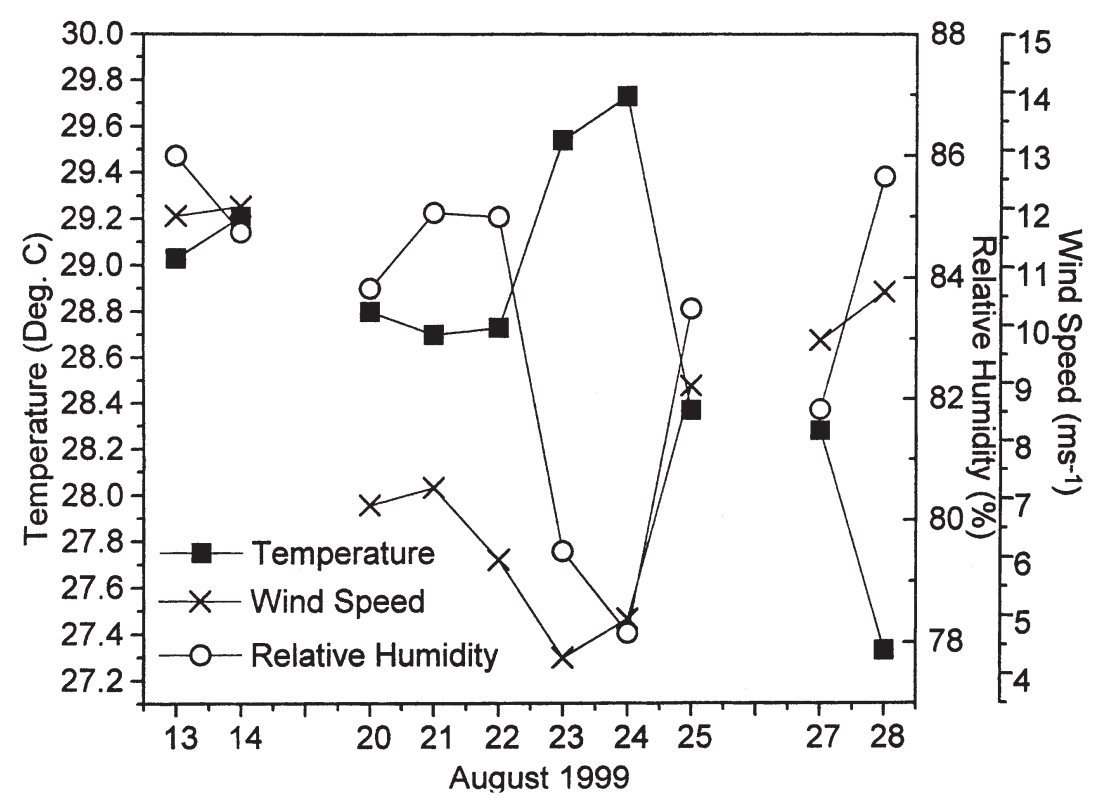

Figure 7. Day-to-day mean variations in meteorological parameters during the cruise period.

and wash-out processes. In spite of the cleansing of the atmosphere over the sea due to rain, the aerosol size spectrum shows bimodal distribution with dominance of accumulation-mode particles. The primary peak is almost two orders greater than the secondary. In the absence of transport of land aerosols which are mostly smaller portions due to various anthropogenic activities, the aerosol size distribution normally shows secondary peak (presence of coarse-mode particles) maximum whereas the present study shows the presence of more submicron particles which clearly reveal the advection of polluted air from land region to the pristine air over the sea. The $\alpha$ and $\beta$ values reveal the presence of larger particles with greater extinction in the observational region.

The daily mean values of total precipitable water content (PWC) and ozone (TCO) during the study period are plotted in figure 11 (a and $b$ ). It can be clearly seen from the figure that the PWC was higher at the beginning, middle and end of the experiment with in between undulations depending upon variations in convective activity. On comparison of PWC variations with those of AOD shown in figure 5 , it reveals one-to-one correspondence between the parameters. Similar comparison between the frames (a) and (b) i.e., between PWC and TCO reveals opposite relationship which can be explained on the basis of mixing of fraction of stratospheric ozone with the wet air-mass in the underlying atmosphere.

An attempt is also made to compare the observed ground-based solar radiometer-derived
TCO values with those retrieved from NASA's Earth-Probe (EP) satellite payload TOMS (Tropospheric Ozone Mapping Spectrometer) during the same period. Such comparison is shown in figure 12. The agreement between the derived quantities is found to be good and the correlation coefficient is 0.87 which is statistically significant.

\section{Conclusions}

The results of the analysis of optical and meteorological data collected using portable multi-band solar radiometers and meteorological kit onboard ORV Sagar Kanya cruise during the second phase of BOBMEX-99 indicate the following:

- Spectral dependence of AOD with higher values at smaller wavelengths and vice-versa. Greater values of $A O D$ in the beginning and ending of the cruise period when the air-mass exchange takes place between the land and marine regions. These variations have been explained by performing the back trajectory analysis.

- Bimodal aerosol size distribution near the coast with maximum concentration of particles at primary mode around $0.2 \mu \mathrm{m}$ radius and secondary mode around $1.0 \mu \mathrm{m}$ particles of fairly high concentrations while power-law size distribution away from the coast. Smaller wavelength exponent $(\alpha)$ and larger Angstrom turbidity coefficient $(\beta)$ indicating abundance of larger aerosol particles with greater extinction at the beginning and ending of the cruise period also confirms this. 

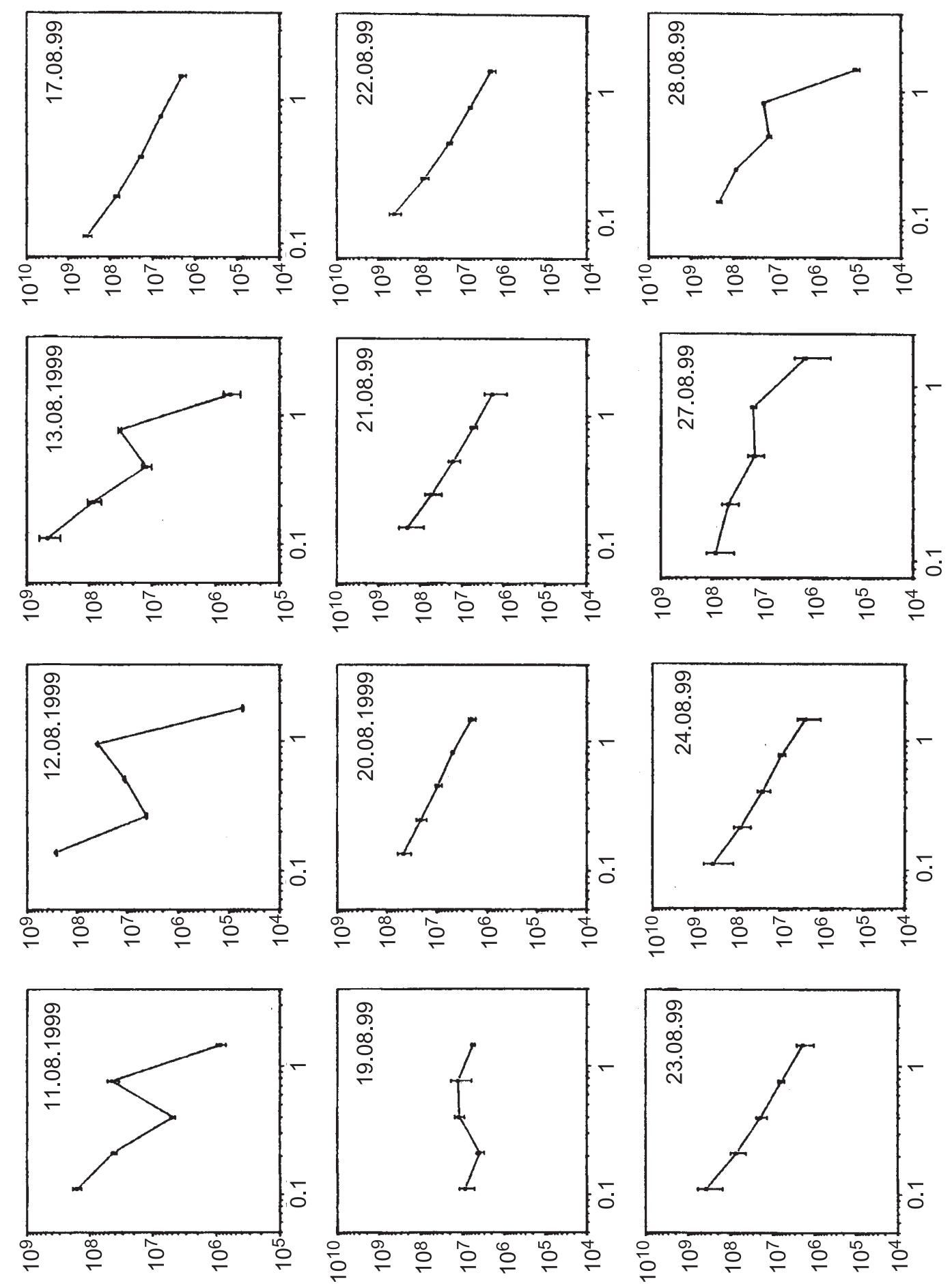

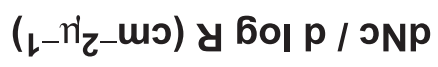




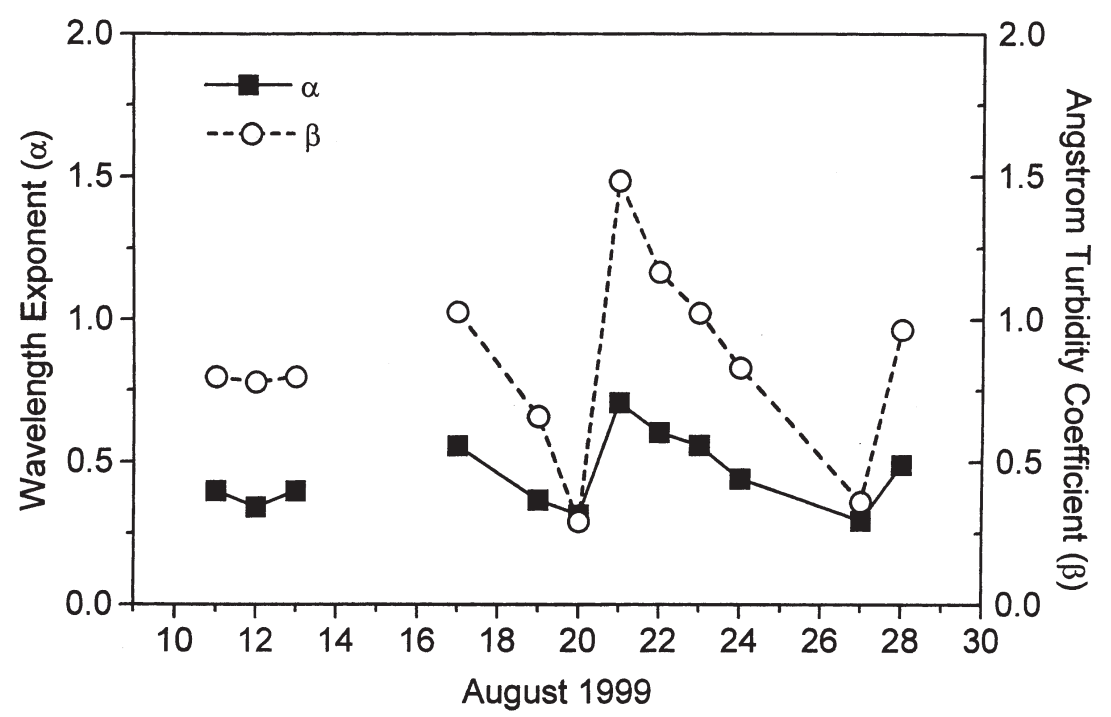

Figure 9. Day-to-day variations in wavelength exponent $(\alpha)$ and Angstrom coefficient $(\beta)$ during the cruise period.
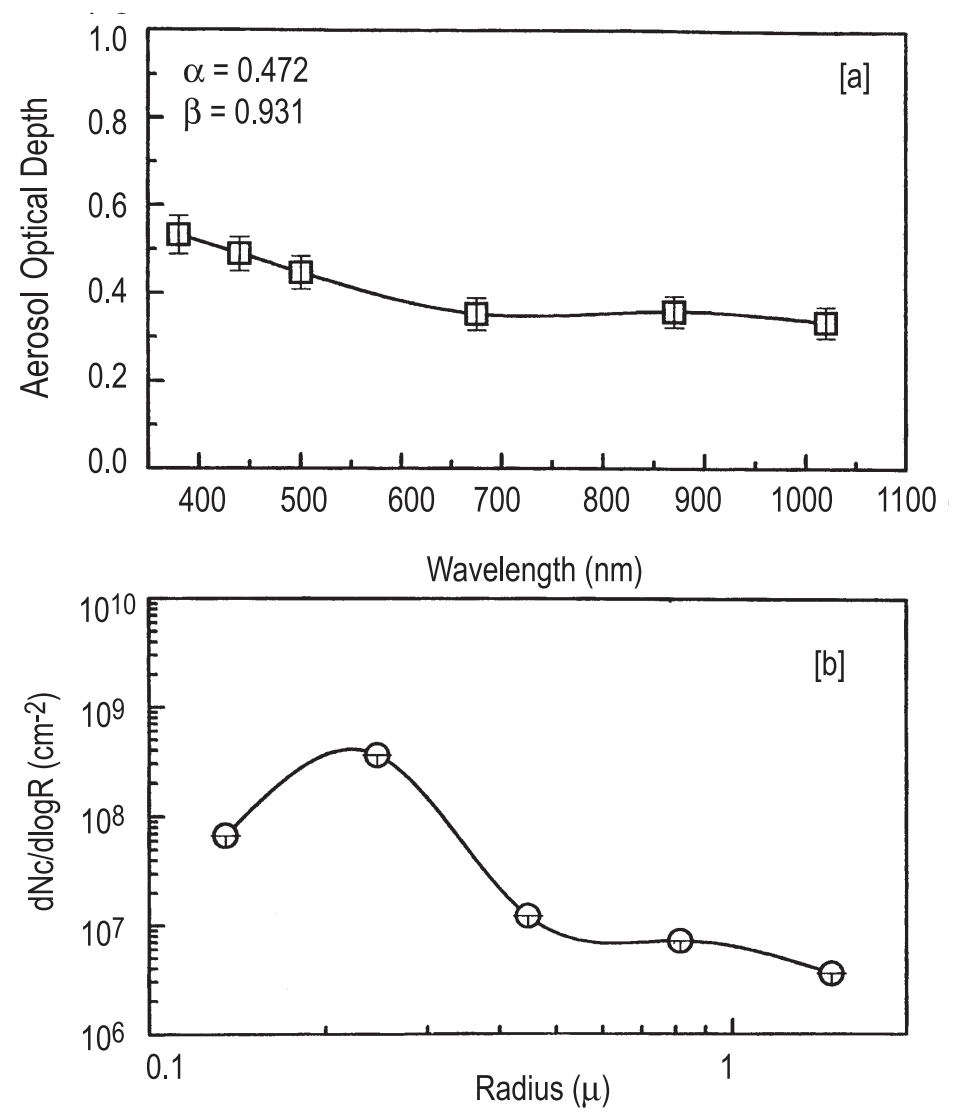

Figure 10. Spectral dependence of AOD and corresponding size distribution during the cruise period. Vertical bars indicate errors in the observations.

- Sharp fall in AOD (about three times) from beginning to the middle of study period when precipitation occurred, which is considered to be due to cloud-scavenging and rain wash-out processes.
- Inverse relationship between the time variations of AOD or PWC and TCO, which is ascribed to the mixing of fraction of stratospheric ozone with aerosol-rich air-mass in the troposphere. 

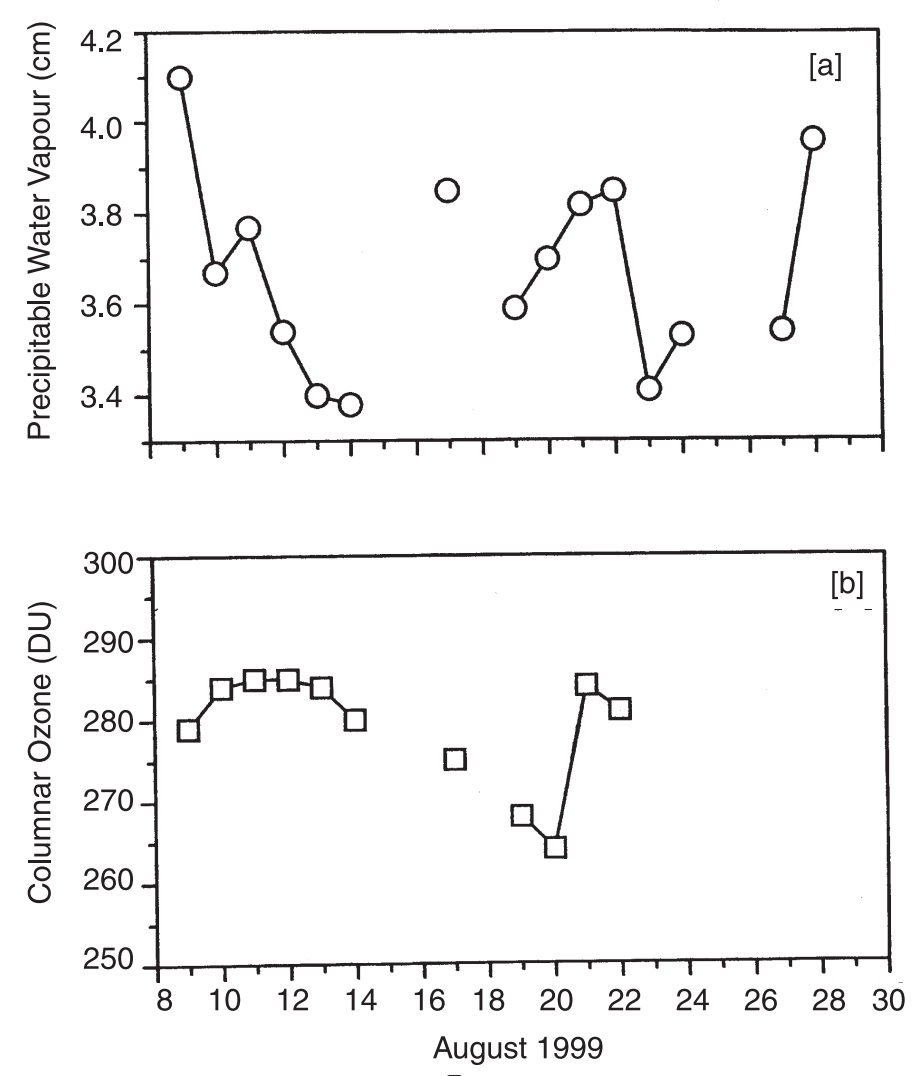

Figure 11. Daily variation in total column (a) precipitable water vapor and (b) Ozone during the cruise period.

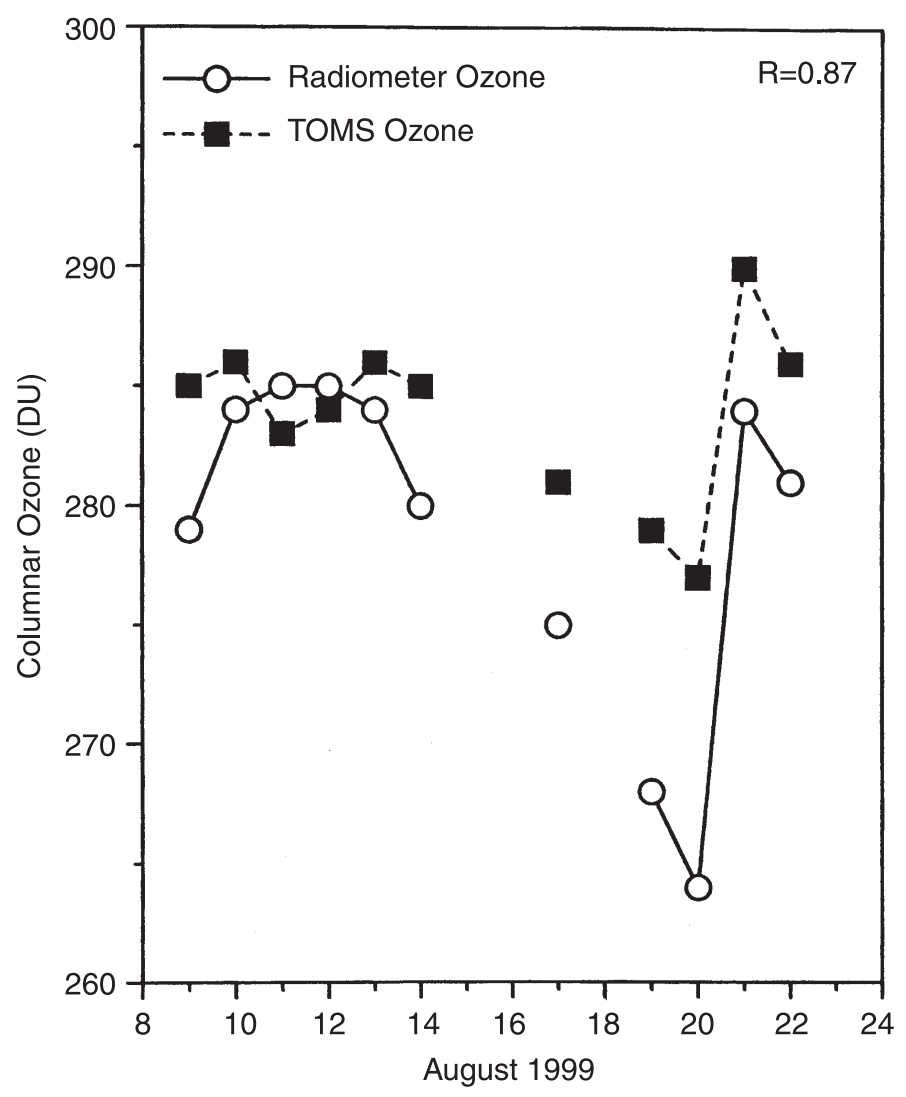

Figure 12. Comparison between radiometer-derived and satellite-measured total column ozone during the cruise period. 
- Fairly good agreement (correlation coefficient = 0.87 ) between radiometer-derived and satelliteobserved TCOs during the study period.

\section{Acknowledgements}

The authors would like to thank the Director, IITM for the encouragement. This work was supported by the National Scientific Program (ICRP) of DST, New Delhi. Thanks are also due to the India Meteorological Department for the meteorological data support. The cooperation received from the captain, officers and crew of the ORV Sagar Kanya ship is gratefully acknowledged. One of the authors (RSM) wishes to thank the INDOEX-India Program for the award of Research Associateship. Thanks are due to the anonymous reviewer for useful comments and suggestions.

\section{References}

Charlson R J, Anderson T L and Rodhe H 1999 Direct climate forcing by anthropogenic aerosols: Quantifying the link between atmospheric sulfate and radiation; Contr. Atmos. Phys. 72 79-94

Devara P C S, Pandithurai G, Raj P E and Sharma S 1996 Investigations of aerosol optical depth variations using spectroradiometer at an urban station, Pune, India; J. Aerosol Sci. 27 621-632

Devara P C S, Maheskumar R S, Raj P E, Dani K K and Sonbawne S M 2001 Some features of column aerosol optical depth, ozone and precipitable water content observed over land during the INDOEX-IFP99; Meteorologische Zeitschraft 10 123-130

Draxler R R and Hess G D 1998 An overview of the HYSPLIT-4 modelling system for trajectories, dispersion and deposition; Aust. Met. Mag. 47 295-308

DST (Department of Science \& Technology) 1996 Indian Climate Research Program - Science Plan, DST, Government of India, New Delhi.
DST (Department of Science \& Technology) 1998 Indian Climate Research Program - Implementation Plan, DST, Government of India, New Delhi.

King M D, Byrne D M, Herman B M and Reagan J A 1978 Aerosol size distributions obtained by inversion of spectral optical depth measurements; J. Atmos. Sci. 35 2153-2167

King M D 1982 Sensitivity of constrained linear inversion to the selection of Lagrange multiplier; J. Atmos. Sci. 39 $1356-1369$

Lohmann U, Feichter J, Cuang C C and Penner J E 1999 Predicting the number of cloud droplets in the ECHAM GCM; J. Geophys. Res. 104 9169-9198

Maheskumar R S, Devara P C S, Dani K K and Raj P E 2001 Optical characteristics of aerosol as inferred from a high spectral resolution radiometer observation over Pune during the INDOEX IFP-99; Current Sci. (Supplement) 80 115-119

Mitra A P 1999 INDOEX (India): Introductory note; Current Science $\mathbf{7 6} 886-889$

Morys M et al 2001 Design, calibration, and performance of MICROTOPS II handheld ozone monitor and sun photometer; J. Geophys. Res. 106 14573-14582

Pandithurai G, Devara P C S, Maheskumar R S, Raj P E and Dani K K 1997 Spectral characteristics of urban aerosols and their connection with relative humidity; Atmos. Res. 45 109-122

Patterson E M and Grams G W 1980 Optical methods for in situ measurements of size distribution and optical properties; Atmos. Tech. 12 3-9

Ramanathan et al 2001 Indian Ocean experiment: an integrated analysis of the climate forcing and effects of the great Indo-Asian haze; J. Geophys. Res. 106 28371-28398

Reagan J A, Thomson L W, Herman B M and Palmer J M 1986 Assessment of atmospheric limitations on the determination of the solar spectral constant from groundbased spectroradiometer measurements; IEEE Trans. Geosci. Remote Sens. GRS-24 258-266

Stair R and Ellis H T 1968 The solar constant based on new spectral irradiance data from 310 to 530 nanometers; $J$. Appl. Meteor. 7 635-644

Teillet P M 1990 Rayleigh optical depth comparison from various sources; Appl. Opt. 29 1897-1900

Young A T 1980 Revised depolarization corrections for atmospheric extinction; Appl. Opt. 19 3427-3428

Young A T 1981 On the Rayleigh scattering optical depth of atmosphere; J. Appl. Meteorol. 20 328-330 